immediately after integration when clinic accommodation, pathways and staffing were in a state of change. The reduced completion rates of a 3-dose course post-integration suggest that clinic access, availability and acceptability for MSM as well as recall arrangements should be explored.

\section{P109 "LOVE THY NEIGHBOUR": AN EVALUATION OF RELIGION AS A POTENTIAL BARRIER TO ACCESSING SEXUAL HEALTH SERVICES FOR GAY AND BISEXUAL MEN IN THE WEST OF SCOTLAND}

Elizabeth Rooney*, Diane Willis. University of Glasgow, Glasgow, UK

\subsection{6/sextrans-2015-052126.152}

Background/introduction Outcome 5 of the Blood Bourne Virus Framework aims for a society where attitudes towards sexual health and HIV are supportive and non-stigmatising. Currently, there is no research as to whether religion is a barrier to attending sexual health services for gay and bisexual men.

Aim(s)/objectives To explore the influence of religion and its relationship to sexuality for gay and bisexual men. To explore if religious beliefs affect attendance at sexual health services and whether current standards of care at sexual health services meet their needs.

Methods Nine participants participated in semi-structured interviews; five sexual health staff; four non-NHS staff including three ordained Ministers from different religions. Questions were about their views around the influence of religious beliefs on the sexual health of gay and bisexual men in the West of Scotland.

Results Four themes were identified: barriers to attending sexual health services, influences of religion/coping behaviour, societal influences and provision of sexual health services. Seven of the nine participants identified that religion is a potential barrier to attending sexual health services. Potential conflict between faith and sexuality affect health seeking behaviour. Implications for practice included staff training, outreach work and referral to Chaplains.

Discussion/conclusion This study finds that religion is a potential barrier to attending sexual health services for gay and bisexual men, particularly if their religion and sexuality are in conflict. It can be linked to risk taking behaviour and stigma is a considerable issue. Recommendations were made for improvements in service provision. Further research is required.

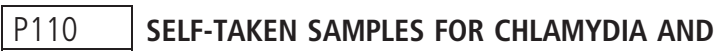 GONORRHOEA IN HIV OUTPATIENTS ARE ACCEPTABLE AND PERCEIVED AS RELIABLE AND COMFORTABLE BY PATIENTS}

Adam Croucher*, Tracey Buckingham, Daniel Richardson. Lawson Unit, Royal Sussex County Hospital, Brighton, UK

\subsection{6/sextrans-2015-052126.153}

Introduction Self-taken samples increase testing for Chlamydia and Gonorrhoea in high-risk asymptomatic populations including HIV-outpatients. Women are offered self-taken vaginal samples; heterosexual men first-pass urine and MSM self-taken rectal and throat samples and first-pass urine. The acceptability of this method of testing is not well understood.
Methods An anonymous paper survey was offered to all patients attending outpatient-HIV clinic June-July 2014. Data collected: age, gender, ethnicity, sexual-orientation; perceptions of selftaken samples; whether they tested that day, and why.

Results 121 surveys were returned. Median age $=45(20-69)$ years; $86 \%$ male; $68 \%$ white British; 73\% homosexual. 61/121 $(50 \%)$ rated STI screening as 'very important', 48/121(39\%) as 'worthwhile': 117/121(96\%) rated offering self-taken samples in routine HIV clinic as appropriate. 86/121(71\%) found the instructions 'easy' to follow and 4/121(3\%) 'difficult'. 78/121 $(64 \%)$ said that they thought that self-taken samples are as reliable compared to clinician-taken and 10/121(8\%) thought they were more reliable. 60/121(50\%) said self-taken samples were as comfortable as clinician-taken; 30/121(25\%) said more comfortable. 33/121(27\%) responders did self-sampling that day; 78/121 (64\%) did not. Participants' reasons for accepting self-taken samples included: 'It's easier/quicker than going to a GUM clinic' (37\%); 'I prefer doing the swabs myself' (25\%). Reasons for not self-sampling included: 'I haven't had any sex since my last sexual health screen' (26\%); 'I was not offered a STI screen today' (20\%); 'I prefer to go to a GUM clinic' (16\%).

Conclusions The self-swab STI screens are acceptable to patients attending HIV outpatients', and are perceived as being as reliable and as comfortable as clinician-taken samples.

\section{P111 DISPERSAL OF A HIV COHORT FOLLOWING THE CLOSURE OF AN OUTREACH CLINIC NECESSITATED BY GOVERNMENT NHS RESTRUCTURING}

Noel B Connolly*, Jonathan Shaw, Justine Mellor, Orla McQuillan. Manchester Centre for Sexual Health, The Hathersage Centre, Manchester Royal Infirmary, 280 Upper Brook Street, Manchester, M13 OFH, UK

\subsection{6/sextrans-2015-052126.154}

Introduction Coalition government health policy has necessitated NHS restructuring. Sexual health provision was opened to competitive tendering with responsibility transferring to local authorities. BASHH/BHIVA published standards and it was expected local sexual health strategy agreements would continue. Methods DGH genitourinary care was provided by university hospital consultants since 2006 facilitated by the local sexual health network, HIV care wasn't due to funding restrictions. To improve care/retention, hub-and-spoke outreach was established in 2011 for $45 \mathrm{HIV}+$ individuals - 1/3 DGH diagnosed, 1/3 transferring from the larger centre, $1 / 3$ from other clinics. Nine (20\%) had previously disengaged. When tendering opened the local authority made no provision to maintain this service.

Results After awarding the tender to a community trust it became apparent that qualified staff would not be available to continue care of the cohort therefore it was maintained by the previous trust. Due to service fragmentation no new local referrals were made. Despite excellent feedback we reluctantly closed as continuing the spoke service became economically unviable. Patients were offered remaining with the same team at the teaching hospital (51\%), transfer to another clinic locally $(20 \%)$ or nationally $(15.5 \%)$ with some moving overseas $(4.5 \%)$. Of concern $4(9 \%)$ are presumed to have disengaged. Several complaints were raised at local authority level.

Discussion Despite upheavals patients must remain at the centre of NHS care. We found BASHH support helpful and suggest dissemination of our experience to others. Highly regarded and well-functioning services are not immune to change and an uncertain future may be expected. 